Textures and Microstructures, Vol. 34, pp. 55-62 Reprints available directly from the publisher Photocopying permitted by license only
(C) 2000 OPA (Overseas Publishers Association) N.V. Published by license under the Gordon and Breach Science Publishers imprint. Printed in Malaysia.

\title{
DEFOCUSING CORRECTION OF X-RAY POLE FIGURES BY MEANS OF NEUTRON POLE FIGURE MEASUREMENT
}

\author{
H. SIEMES ${ }^{a, *}$, C.A. ROSIÈRE ${ }^{b}$, P. HACKSPACHER ${ }^{c}$, \\ W. SCHÄFER ${ }^{d}$ and E. JANSEN ${ }^{d}$ \\ a Institut für Mineralogie und Lagerstättenlehre, RWTH-Aachen, \\ Wüllnerstr. 2, D-52056 Aachen, Germany; ' Instituto de Geociências, \\ Universidade Federal de Minas Gerais, Av. Antônio Carlos 6627, \\ Belo Horizonte CEP 31270-901, MG, Brazil; ' ${ }^{\mathrm{c}}$ Departamento de \\ Petrologia e Metalogenia, Universidade Estadual São Paulo, \\ P.O. Box 178, Rio Claro, CEP 13506-900, SP, Brazil; \\ d Mineralogisches Institut Universität Bonn, Forschungszentrum Jülich, \\ D-52425 Jülich, Germany
}

(Received 10 December 1999)

A rather simple empirical defocusing correction method is described which makes use of $\mathrm{X}$-ray and neutron measurement of pole figure data from a sample with a weak preferred orientation.

Keywords: X-ray texture analysis; Neutron texture analysis; Defocusing correction

\section{INTRODUCTION}

The measurement of X-ray pole figure data in the back reflection mode is inherently connected with a loss of intensity with increasing tilt angle $\chi$. The tilt angle at which the defocusing effect begins, depends mainly on the settings of the texture goniometer as: $2 \theta$ of the selected plane ( $h k l)$, the configuration of the slits. In optimum cases this tilt angle is as high as $75^{\circ}$, but may be as low as $20^{\circ}$. The correction of the defocusing effect

\footnotetext{
* Corresponding author. Institut für Mineralogie und Lagerstättenlehre, RWTH, Bunsenstr 8, D-52056 Aachen, Germany.
} 
can be performed conveniently by means of a sample with a random distribution of the crystals (see e.g. Wcislak et al., 1993), but may also be done by theoretical methods (see e.g. Wenk, 1998). Unfortunately it is often very difficult or impossible to find or prepare a random sample of minerals and rocks.

In the course of the PROBRAL-project it was necessary to measure the preferred orientation of a series of hematite ores from the Quadrilátero Ferrífero District, Minas Gerais, Brazil. In order to correct the measurements a hematite sample from South Africa with a very weak preferred orientation was used which has been measured by $\mathrm{X}$-rays and by neutrons.

The neutron pole figures were measured at the Research Center Jülich, Germany using a position-sensitive detector (Will et al., 1989). The X-ray pole figures are accomplished at the Geological Department (UNESP), Rio Claro, by means of a Siemens/Bruker X-ray texture goniometer in the rot-trans motion of the specimen.

\section{THE CORRECTION PROCEDURE}

For the correction procedure samples from a hematite hand specimen from South Africa were used. Microscopic studies of this ore reveal a grain size layering with a thickness of $200-1200 \mu \mathrm{m}$. Within the fine grained layers the grain sizes vary between 5 and $25 \mu \mathrm{m}$ and in the coarse grained layers between 80 and $175 \mu \mathrm{m}$. The penetrative weak preferred orientation is presented in Fig. 1(a) by means of the neutron pole figures of the (003)-, (110)- and (012)-reflections using a cylinder of $1 \mathrm{~cm}^{3}$. From these pole figures mean density profiles were calculated (Fig. 1(b)). For the X-ray measurement a flat sample of 1.5 by $1.5 \mathrm{~cm}^{2}$ was used to accomplish the (110)- and (012)-pole figures in the same orientation as the neutron pole figures (Fig. 2(a)) and to calculate the related mean profiles (Fig. 2(b)). The pole figures and the profiles reveal that the $\mathrm{X}$-ray measurement is strongly influenced by defocusing effects. The mean X-ray density profiles were adjusted to the density at $0^{\circ}$ of the neutron profiles (Fig. 2(c)) assuming that at least this density was measured without any loss of intensity. Finally the mean X-ray profile densities were divided by the mean neutron profile densities (Fig. 3 and Table I). 
(a)

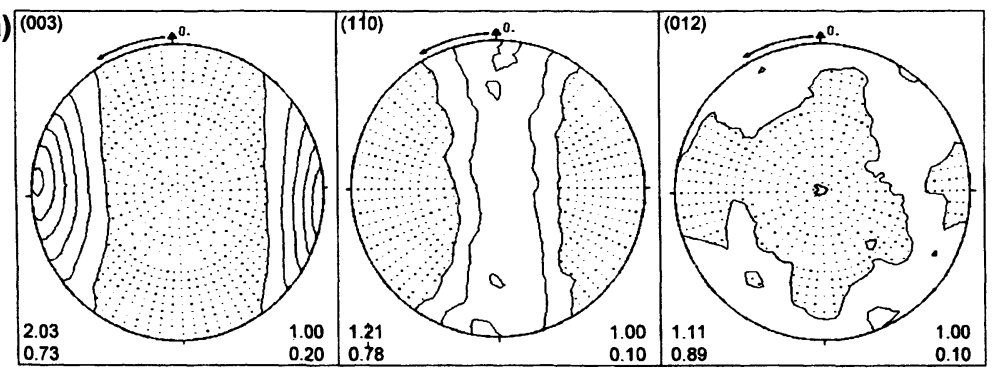

(b)

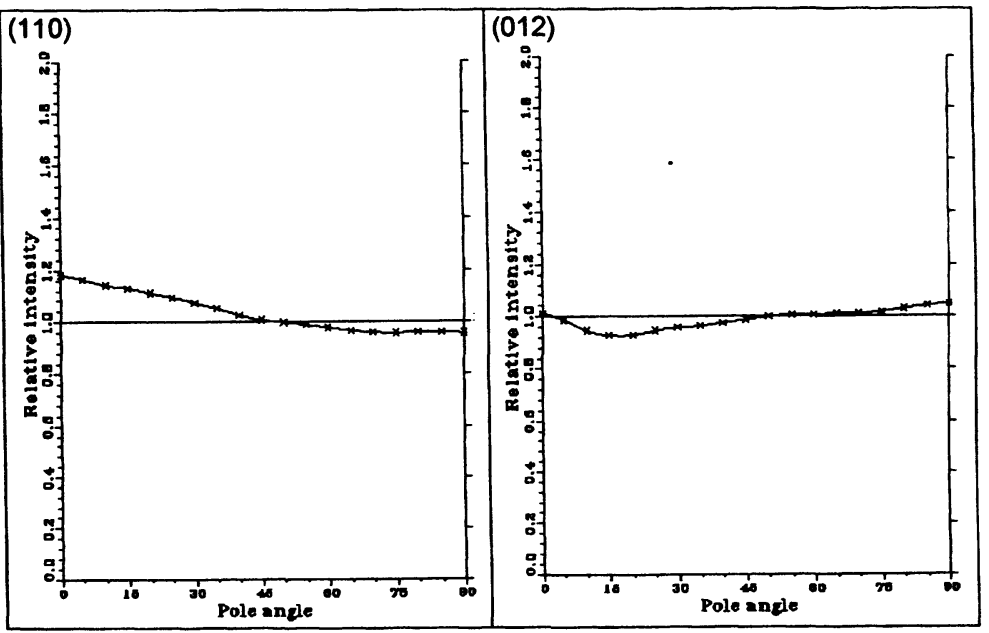

FIGURE 1 Weak preferred orientation of a hematite sample from South Africa. (a) Neutron pole figures of three reflections. Below each pole figure are indicated in the lower left corner the maximum and minimum density in m.r.d. and in the lower right corner the first contour line and the contour line interval. (b) Mean density profiles derived from the neutron pole figures.

The first 4 quotients (Table I) are close to one indicating that up to $15^{\circ}$ no correction is necessary. The defocusing begins above $15^{\circ}$ and very strongly increases up to $80^{\circ}$. After setting the first 4 values to 1.000 the quotients were used as correction factors. For the (104)-pole figures the correction data of the neighboring (110)-reflection were used. The correction factor for the highest pole angle can often cause an excessive density value, in this case the maximum pole angle should be reduced to a lower angle, e.g. $70^{\circ}$. 

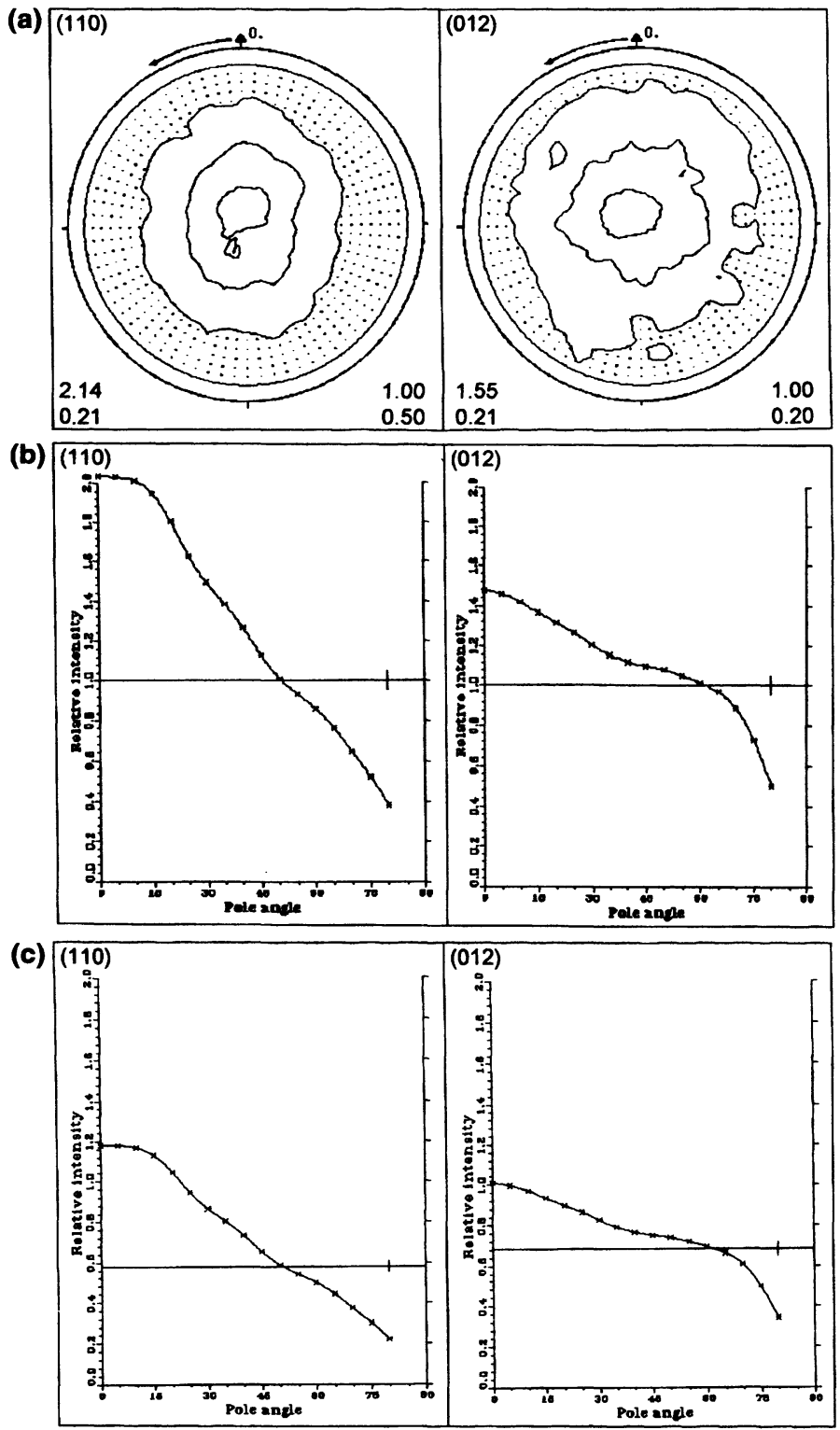

FIGURE 2 Weak preferred orientation of a hematite sample from South Africa. (a) X-ray pole figures of two reflections. (b) Mean density profiles derived from the $\mathrm{X}$-ray pole figures. (c) Mean X-ray density profiles adjusted to the density at $0^{\circ}$ of the neutron profiles. 


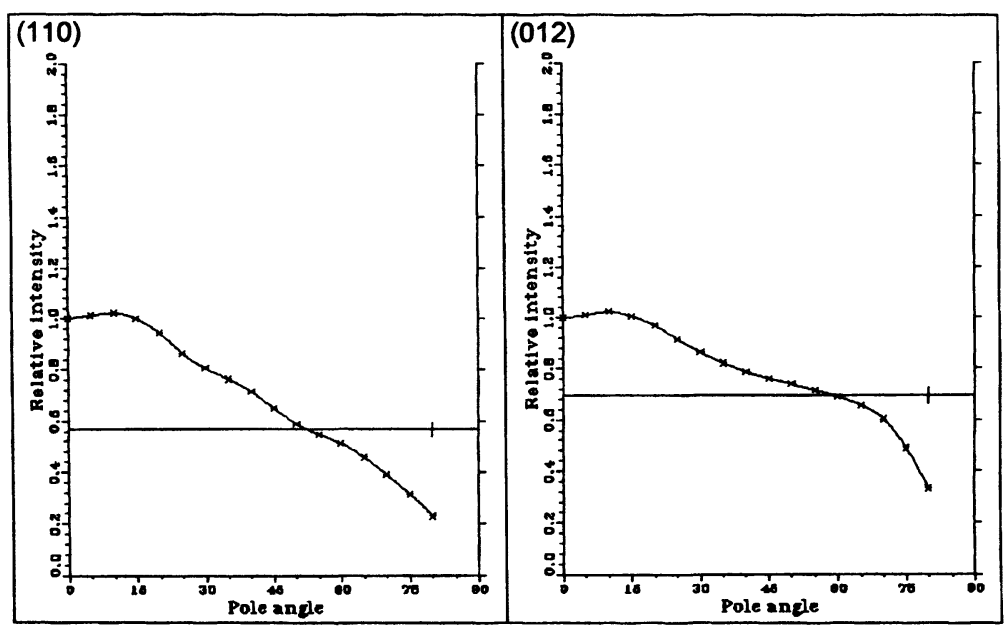

FIGURE 3 The mean X-ray density profiles of the hematite sample from South Africa are divided by the mean neutron profiles.

TABLE I The quotients of the mean X-ray density profiles and the mean neutron profiles

\begin{tabular}{lllllllllll}
\hline \multicolumn{1}{l}{$(110)$ reflection } & & & & & & & & & \\
1.000 & 1.013 & 1.024 & 1.002 & 0.944 & 0.865 & 0.806 & 0.765 & 0.715 & 0.650 & 0.589 \\
0.548 & 0.511 & 0.459 & 0.389 & 0.315 & 0.230 & & & & & \\
$(012)$ reflection & & & & & & & & & \\
1.000 & 1.010 & 1.025 & 1.006 & 0.969 & 0.914 & 0.862 & 0.821 & 0.787 & 0.762 & 0.740 \\
0.716 & 0.690 & 0.656 & 0.601 & 0.490 & 0.332 & & & & & \\
\hline
\end{tabular}

\section{EXAMPLE}

Uncorrected and corrected X-ray pole figures perpendicular to the foliation and to the lineation of the hematite sample MCAE67, Cauê Mine, Quadrilátero Ferrífero District, Minas Gerais are shown in Fig. 4. The main structure of this sample is an axial plane schistosity (foliation) that transposes the earlier isoclinally folded planar fabric, probably the primary banding. The microstructure of the sample displays fine platy hematite (specularite) $(0.1-0.3 \mathrm{~mm}$ in length) enveloping martite crystals $(\sim 0.3 \mathrm{~mm} \oslash)$ and fine equidimensional (granoblastic) hematite aggregates $(0.05-0.1 \mathrm{~mm})$. The ore constitutes about $70 \%$ specularite, $20-30 \%$ granoblastic hematite and approx. $10 \%$ 

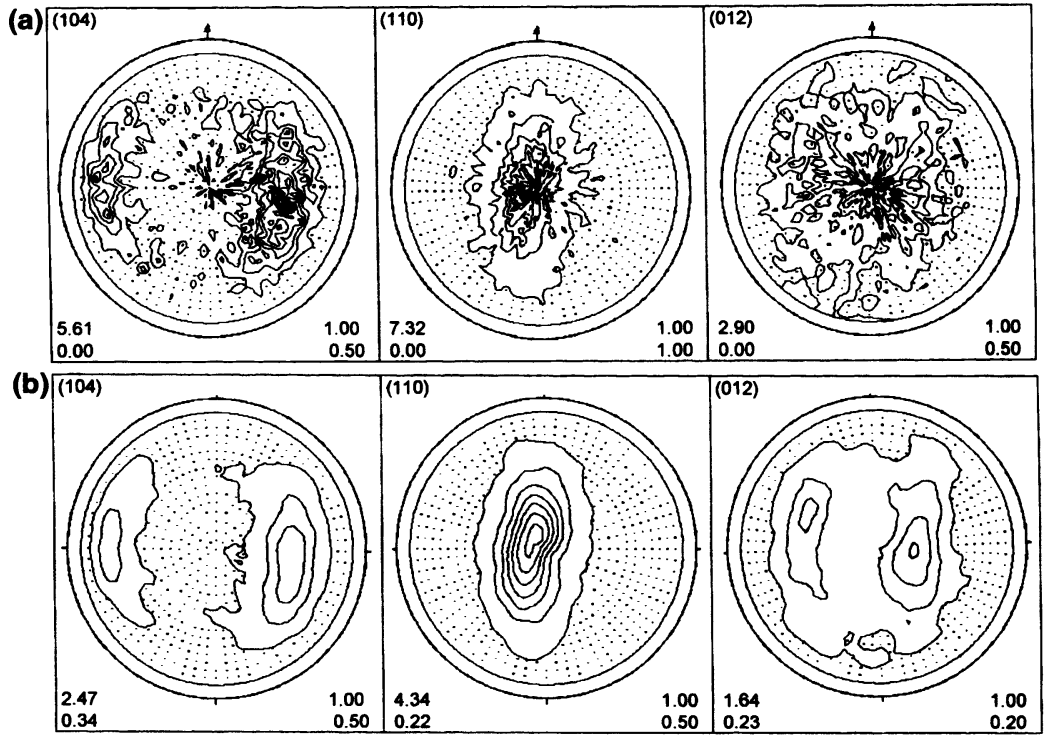

(c)

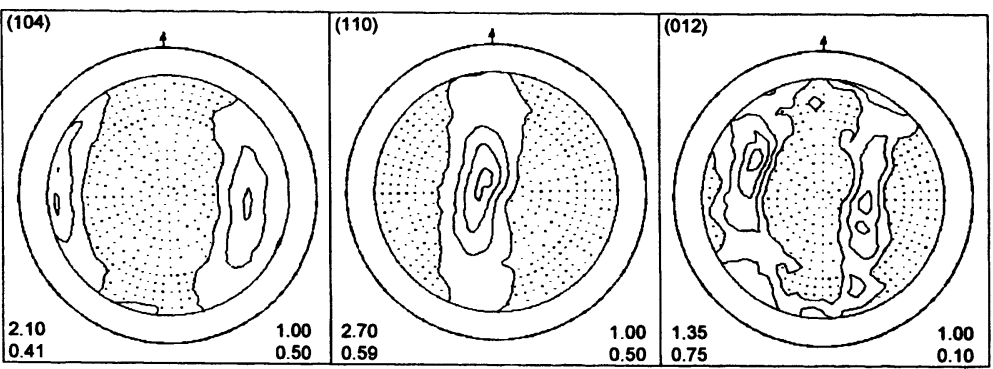

FIGURE 4 Pole figures perpendicular to the foliation and to the lineation of the hematite sample MCAE67, Cauê Mine, Quadrilátero Ferrífero District, Minas Gerais, Brazil. (a) Uncorrected X-ray pole figures. (b) Smoothed, uncorrected X-ray pole figures. (c) Defocusing corrected X-ray pole figures.

martite with magnetite relicts. The heterogeneity of the fabric and the wavy disposition of the specularite plates result in a high fluctuation of intensities as depicted in Fig. 4(a). After applying the smoothing routine (Traas et al., 1994) the pole figures show smooth contour lines and a distinct maxima-minima configuration (Fig. 4(b)). In the next step the defocusing correction was applied and in Fig. 4(c) the final result is presented revealing the well known type of pole figures from hematite ores of banded iron formation (e.g. Rosière et al., 1999). Meanwhile 
a series of texture measurements were successfully corrected e.g. Hackspacher et al. (1999).

\section{CONCLUSIONS}

The derivation of defocusing correction factors by means of a sample with a weak preferred orientation which has been measured by neutron diffraction seems to be promising. However, requirement is that the sample has a homogeneous and penetrative preferred orientation in order to guarantee that both, X-rays and neutrons, see the same texture. Once a suitable sample has been found and measured by neutron diffraction this sample can be always used as standard for defocusing corrections in X-ray measurements.

\section{Acknowledgments}

We like to thank $\mathrm{H}$. Klein, Institut für Metallphysik, Universität Clausthal, and K. Kunze, Geologisches Institut, ETH-Zürich for their $\mathrm{X}$-ray measurements of the hematite sample from South Africa in order to control the correction procedure with different X-ray equipment. Financial support by the PROBRAL (CAPES/DAAD)- and FINEP/ PADCT project: 'Texture, physical anisotropy and metallurgy of iron ores of the Iron Quadrangle (Minas Gerais, Brazil)' is gratefully acknowledged. Financial support by the DFG permitted the presentation of this contribution at the ICOTOM12 in Montreal.

\section{References}

Hackspacher, P.C., Oliveira Jr., V.T., Siemes, H., Rosière, C.A. and Moreno, M.M.T. (1999) Textural contrast and crystallographic control of banded iron formation of the Conceição mine, Quadrilátero Ferrífero, Brazil. Göttinger Arbeiten zur Geologie und Paläontologie (International Conference, Textures and Physical Properties of Rocks, edited by B. Leiss, K. Ullemeyer and K. Weber) Vol. SB4, pp. 58-60.

Rosière, C.A., Siemes, H., Quade, H., Brokmeier, H.-G. and Jansen, E.M. (1999) Microstructures, textures and deformation mechanisms in hematite. Journal of Structural Geology (Submitted).

Traas, C., Siemes, H. and Schaeben, H. (1994) Smoothing pole figures using tensor products of trigonometric and polynomial splines. Proceedings of the 10th International Conference on Textures of Materials ICOTOM 10, Ed. H.J. Bunge. Materials Science Forum, 157-162, 453-458. 
Wcislak, L., Bunge, H.-J. and Nauer-Gerhardt, C.U. (1993) X-ray diffraction texture analysis with a position sensitive detector. $Z$. Metallkunde, 84, 479-493.

Wenk, H.R. (1998) Pole figure measurements with diffraction techniques. In: Texture and Anisotropy - Preferred Orientation in Polycrystals and their Effect on Material Properties, Ed. U.F. Kocks, C.N. Tomé and H.-R. Wenk, pp. 126-177, Cambridge University Press, Cambridge.

Will, G., Schäfer, W. and Merz, P. (1989) Texture analysis by neutron diffraction using a linear position sensitive detector. Textures and Microstructures, 10, 375-387. 